\title{
PENGARUH JUS APEL TERHADAP PENURUNAN TEKANAN DARAH PADA LANSIA HIPERTENSI DI PUSKESMAS MUARA KAMAN
}

\section{The Effect Of Apple Juice On Blood Pressure Decrease In Elderly People With Hypertension At Muara Kaman Community Health Center}

\author{
Siti Khoiroh ${ }^{1}$, Andri ${ }^{2}$ \\ ${ }^{1}$ Dosen Prodi Ilmu Keperawatan Fakultas Ilmu Kesehatan UMKT \\ ${ }^{2}$ Mahasiswa Prodi Ilmu Keperawatan Fakultas Ilmu Kesehatan UMKT
}

\begin{abstract}
ABSTRAK
Latar Belakang : hipertensi merupakan kondisi tekanan darah tinggi pada pembuluh darah arteri yang berlangsung secara terus-menerus dalam jangka waktu yang lama. Hipertensi dapat ditanggulangi dengan dua cara yaitu dengan cara farmakologi dan non-farmakologi. Pengobatan farmakologi biasanya menggunakan obat sedangkan non farmakologi salah satunya yaitu dengan mengkonsumsi jus apel.

Tujuan Penelitian : Untuk mengetahui pengaruh jus apel terhadap penurunan tekanan darah pada lansia hipertensi di Puskesmas Muara Kaman.

Metode : Rancangan penelitian ini menggunakan desain quasi eksperimen (eksperimen semu) dengan menggunakan rancangan pretest posttest with control group. Sampel penelitian adalah responden hipertensi di Puskesmas Muara Kaman sebanyak 30 responden dibagi menjadi 2 kelompok, 15 kelompok intervensi dan 15 kelompok kontrol. Teknik pengambilan sampel dengan cara purposive sampling. Instrumen penelitian berupa stethoscope dan sphygmomanometer, analisa data menggunakan uji t dependen dan uji t independen.

Hasil penelitian : Ada pengaruh yang signifikan antara pemberian jus apel pretest dan posttest pada kelompok intervensi $(\mathrm{P}$ value $=0,000 ; \mathrm{P}<0,005)$. Selisih rata-rata tekanan darah sistolik pada kelompok intervensi dan kelompok kontrol juga memiliki perbedaan yang signifikan $(\mathrm{P}$ value $=$ $0,002 ; \mathrm{P}<0,05)$, sedangkan Selisih rata-rata tekanan darah diastolik pada kelompok intervensi dan kelompok kontrol juga memiliki perbedaan yang signifikan ( $\mathrm{P}$ value $=0,039 ; \mathrm{P}<0,05$ ).

Kesimpulan : Hasil penelitian ini menunjukan bahwa mengkonsumsi jus apel dapat berpengaruh pada tekanan darah penderita hipertensi dengan mengkonsumsi secara rutin.

Saran : Perawat dan masyarakat dapat menggunakan jus apel sebagai salah satu penanganan untuk penderita hipertensi selain obat-obatan antihipertensi.
\end{abstract}

Kata kunci : Hipertensi, Jus apel

\section{ABSTRACT}

Background : Hypertension is a condition of high blood pressure in the arteries that lasted continuously for the long term. Hypertension can be overcome in two ways: pharmacology and nonpharmacology. Pharmacology treatment usually use medicine while one of the ways for nonpharmacology treatment is to consumes apple juice.

Research Objective : The aim of this research is to know the effect of apple juice on blood pressure decrease in elderly people with hypertension at Muara Kaman Community Health Center.

Methods : The design of this research used quasi experimental design (quasi experiment) with pretest posttest control group design. The sample of the research was hypertensive respondents at Muara Kaman Community Health Center as many as 30 respondents were divided into 2 groups, 15 intervention groups and 15 control groups. The sampling technique used purposive sampling. The research instruments were stethoscope and sphygmomanometer, data analysis using $t$ test dependent and t test independent.

Results : There were a significant influence between pretest and posttest of apple juice in the intervention group $(P$ value $=0,000 ; P<0.005)$. The mean difference in systolic blood pressure in the intervention group and the control group also had significant differences $(P$ value $=0.002 ; P$ 
$<0.05)$, where as the mean difference in diastolic blood pressure in the intervention group and the control group also had significant differences ( $P$ value $=0,039 ; P<0,05)$.

The Conclusions : The results of this research showed that consumes apple juice gives an effect on the blood pressure of hypertensive patients by consumes regularly.

The Suggestions : Nurses and the public can use apple juice as one of the ways to handling to hypertension sufferers besides antihypertensive drugs.

Keywords : Hypertension, Apple Juice, Elderly

\section{PENDAHULUAN}

Lansia adalah orang yang usianya 60 tahun atau lebih yang mengalami perubahan biologi, fisik, kejiwaan, dan sosial, baik laki-laki maupun perempuan. Perubahan ini akan berpengaruh terhadap aspek kehidupannya termasuk kesehatannya. Oleh karena itu kesehatan lanjut usia perlu mendapatkan perhatian khusus dan tetap terpelihara serta ditingkatkan agar kemampuannya dapat ikut serta berperan aktif dalam pembangunan (Depkes RI, 2007).

Menurut Riskesdas, (2013). Jumlah lansia di Indonesia mencapai 18,55 juta orang. Dari jumlah tersebut, Provinsi daerah Istimewa Yogyakarta, merupakan daerah paling tinggi jumlah lansianya, disusul provinsi Jawa Timur (10,37\%), Jawa Tengah (10,35), Bali (9,79\%), Sulawesi Utara $(8,47 \%)$, Sulawesi Selatan $(8,34 \%)$, Sumatera barat $(8,09 \%)$, Nusa Tenggara Timur $(7,47 \%)$, Nusa Tenggara Barat (7,23\%), Lampung (7,22\%), dan Jawa Barat (7,05\%), Kalimantan Timur $(4,03 \%)$.

Hipertensi merupakan kondisi tekanan darah tinggi pada pembuluh darah arteri yang berlangsung secara terus-menerus dalam jangka waktu yang lama. Hipertensi meningkatkan peluang terjadinya penyakit ginjal dan kardiovaskuler serta gangguan sistem saraf dan retinopati. Hipertensi dipengaruhi oleh gaya hidup seperti aktivitas fisik kurang,kebiasaan merokok, konsumsi alkohol berlebih, serta asupan sodium tinggi sedangkan asupan sayur dan buah rendah (Aiska, 2013). Hipertensi juga diberi julukan "The Silent disease" karena pada umumnya penderita tidak mengetahui mengalami hipertensi sebelum memeriksakan tekanan darahnya. Hipertensi juga dikenal sebagai heterogeneous group of disease karena dapat menyerang siapa saja dari berbagai kelompok umur dan kelompok sosial ekonomi (Astawan, 2007).

Berdasarkan data WHO tahun 2011 ada satu milyar orang di dunia menderita hipertensi dan dua per-tiga diantaranya berada di Negara berkembang yang berpenghasilan rendah-sedang. Prevalensi hipertensi pada tahun 2025 mendatang akan terus meningkat, diperkirakan sebanyak $29 \%$ penduduk orang dewasa di seluruh dunia atau mencapai sekitar 1,5 milyar orang akan terkena serangan hipertensi.

Sedangkan di Indonesia, sekitar 31,7\% dari total penduduk menderita hipertensi pada 5 tahun terakhir (data Riset Kesehatan Dasar Kemenkes RI 2007). Prevalensi hipertensi di Indonesia sebesar 26,5\% pada tahun 2013, tetapi yang terdiagnosa oleh tenaga kesehatan atau riwayat minum obat hanya sebesar 9,5\%, hal ini menandakan bahwa sebagian besar kasus hipertensi di masyarakat belum terdiagnosa dan terjangkau pelayanan kesehatan (Kemenkes RI, 2013). Sedangkan menurut data Riset Kesehatan Dasar (2013), melalui pengukuran penduduk pada umur $\geq 18$ tahun angka prevalensi hipertensi di Kalimantan Timur yaitu 29,6\%, data ini menunjukan Kalimantan Timur Menduduki urutan ketiga setelah Bangka Belitung 30,9\% Kalimantan Selatan 30,8\%. Di Provinsi Kalimantan Timur berdasarkan hasil pengukuran tekanan darah ditemukan prevalensi sebesar 33,8\% pada Kabupaten Kutai Kartanegara yang menempatkan kabupaten tersebut menempati posisi kedua dengan prevalensi hipertensi terbanyak (Riskesdas, 2013).

Tingginya angka kejadian hipertensi di Indonesia, memerlukan penanganan yang cepat dan tepat. Pengobatan hipertensi bisa dilakukan secara farmakologi dan non farmakologi. Secara farmakologi yaitu dengan pemberian obat Alfa-bloker, prazosin menyebabkan vasodilatasi arteri dan vena sehingga jarang menimbulkan takikardi. Obat ini menurunkan tekanan darah dengan cepat setelah dosis pertama, sehingga harus hati-hati pada pemberian pertama. Untuk pengobatan hipertensi, alfa-bloker dapat digunakan bersama obat antihipertensi lain seperti captopril, 
benazepril, delapril, fisonopril, perinopril dan silazapril palmer (WHO, 2007). Sedangkan penanganan hipertensi dengan memberikan pengobatan non farmakologi seperti dengan memakan buah-buahan yang dapat menggantikan fungsi vasodilatasi pada pengobatan non farmakologi bahkan tanpa efek samping, salah satu buahan yang bisa dikonsumsi yaitu buah apel. (Amran, 2010).

Buah apel (Malus sylvestris) dimana buah apel mempunyai kandungan vitamin A, B1, B2, B3, B5, B6, dan vitamin C. dan Terdapat pula sejumlah mineral seperti Kalium, magnesium, kalsium, zat besi, zinc. unsur lainnya seperti fitokimian, tanin, serat, baron, asam tartar sangat baik untuk mengobati Hipertensi. Apel telah diketahui sebagai sumber yang kaya senyawa antioksidan dan kimia yang disebut flavonoid yang sehat untuk jantung dan baik untuk sistem kardiovaskular pada umumnya, sehingga jika jantung sehat maka tekanan darah juga akan sehat. Kandungan zat gizi yang menonjol pada apel adalah kalium, apel terutama yang berwarna merah tergolong memiliki kandungan kalium cukup tinggi. Kalium meningkatkan ekskresi $\mathrm{Na}$ dan menurunkan sekresi rennin, vasodilatasi arteriol dan menurunkan respon terhadap vasokonstriktor endogen.

Berdasarkan fenomena dan hasil studi pendahuluan yang dilakukan, peneliti mendapatkan data di puskesmas Muara Kaman setiap tahun penderita hipertensi di Puskesmas Muara Kaman selalu bertambah dari data sebelumnya didapatkan hasil penderita hipertensi 250 orang dengan jumlah lansia 40 orang sedangkan dari data setahun terakhir ini jumlah penderita hipertensi yang berdasarkan kunjungan total keseluruhan 289 orang dengan rentang usia 20 tahun hingga $>70$ tahun, sedangkan jumlah data lansianya 59 orang data ini didapatkan berdasarkan hasil rekam medis pasien yang datang dan diperiksa tekanan darahnya di Puskesmas tahun 2016. Kondisi ini tidak dapat diabaikan mengingat individu yang memiliki tekanan darah tinggi menyebabkan jantungnya bekerja ekstra keras, akhirnya kondisi ini berakibat terjadinya kerusakan pada pembuluh darah jantung, ginjal, dan otak (Mardiana, 2013).

Berdasarkan latar belakang diatas maka penulis tertarik untuk melakukan penelitian tentang "Pengaruh Pemberian Jus Apel Terhadap Penurunan Tekanan Darah Pada Lansia Hipertensi Di Puskesmas Muara Kaman".

\section{METODE PENELITIAN}

Penelitian ini menggunakan jenis penelitian kuantitatif. Jenis rancangan penelitian ini menggunakan desain quasy eksperimen (eksperimen semu) dengan tipe (pretest posttest with control group). Populasi yang dimaksud dalam penelitian ini semua lansia yang menderita hipertensi yang ada di Puskesmas Muara Kaman tahun 2016, berjumlah 59 responden dengan sampel menggunakan purposive sampling dengan jumlah responden 30 responden masing-masing 15 untuk intervensi dan 15 untuk kontrol. Dalam penelitian ini peneliti menggunakan instrument penelitian berupa stethoscope, sphygmomanometer yang telah dilakukan uji kalibrasi dan jus apel. Hasil uji normalitas data pada penelitian ini adalah tekanan darah sistolik dan diastolik pada kelompok intervensi dan kelompok kontrol baik pretest maupun postest didapatkan nilai p-value $>0,05$, berarti data berdistribusi normal, maka uji statistik yang digunakan adalah uji parametrik yaitu paired sampel t-test untuk sampel berpasangan. Sedangkan uji yang digunakan untuk mengetahui perbedaan selisih rata-rata antara satu kelompok dengan kelompok yang lain,dimana antara satu kelompok dengan kelompok lainnya tidak saling berhubungan adalah $t$-test independent.

\section{HASIL PENELITIAN}

Hasil uji karakftersitrik responden berdasarkan jenis kelamin.

\begin{tabular}{llcccc}
\hline No & $\begin{array}{c}\text { Jenis Kelamin } \\
\text { Responden }\end{array}$ & \multicolumn{2}{c}{ Kelompok Intervensi } & \multicolumn{2}{c}{ Kelompok Kontrol } \\
\hline & & F & \% & F & \% \\
\cline { 3 - 6 } 1 & Laki-laki & 7 & 46,7 & 4 & 26,7 \\
2 & Perempuan & 8 & 53,3 & 11 & 73,3 \\
& Jumlah & 15 & & 15 & \\
\hline
\end{tabular}

Sumber : Data Primer 
Dari hasil data bahwa responden yang mengalami hipertensi dari hasil penelitian diketahui bahwa pada kelompok intervensi responden laki-laki sebanyak 7 responden $(46,7 \%)$ dan responden perempuan sebanyak 8 responden $(53,3 \%)$ dan untuk kelompok kontrol, responden laki-laki sebanyak 4 responden $(26,7 \%)$ dan responden perempuan sebanyak 11 responden $(73,3 \%)$. Dengan ini diperoleh data bahwa responden yang mengalami hipertensi lebih banyak terdapat pada perempuan.

Hal ini dikarenakan perempuan biasanya memiliki tekanan darah yang lebih tinggi setelah menopouse. Potter \& Perry (2007) menjelaskan bahwa menopouse secara khas terjadi antara usia 45-60 tahun. Wanita yang belum mengalami menopause dilindungi oleh hormon estrogen yang berperan dalam meningkatkan High Density Lipoprotein (HDL). Kadar kolesterol HDL yang tinggi merupakan faktor pelindung dalam mencegah terjadinya proses aterosklerosis. Efek perlindungan esterogen dianggap sebagai penjelasan adanya imunitas wanita mulai kehilangan sedikit demi sedikit hormone esterogen yang selama ini melindungi pembuluh darah dari kerusakan setelah lanjut usia.

Selain faktor hormon penyebab hipertensi pada wanita bisa disebabkan oleh faktor obesitas, konsumsi garam berlebih, stress, dan faktor keturunan.

karakftersitrik responden berdasarkan Umur.

\begin{tabular}{llccccc}
\hline $\begin{array}{c}\text { Kategori } \\
\text { Kelompok }\end{array}$ & Mean & Median & SD & Min & Max & 95\% CL \\
\hline Intervensi & 67,07 & 68,00 & 3,595 & 60 & 70 & $65-69$ \\
Kontrol & 65,13 & 65,00 & 3,642 & 60 & 70 & $63-67$ \\
\hline
\end{tabular}

Sumber: Data Primer

Berdasarkan hasil penelitian diperoleh gambaran bahwa pada 15 responden intervensi dan 15 responden kontrol yang terlibat dalam penelitian ini sebagian besar berusia 67 tahun untuk kelompok intervensi dan untuk kelompok kontrol sebagian besar adalah usia 65 tahun, dan usia responden terendah ialah 60 tahun dan tertinggi 70 tahun.

Dari hasil analisa diatas, rata-rata responden termasuk dalam usia lanjut. Amilawaty (2007) menyatakan bahwa tekanan darah secara alami cenderung meningkat seiring dengan bertambahnya usia. Bangun (2002) dalam Patminingsih (2010) yang menyatakan bahwa penyakit hipertensi berkembang saat umur seseorang telah mencapai paruh baya yaitu pada umur 40-60 tahun. Applegate (1998) dalam Patminingsih (2010) menyatakan bahwa pada umumnya tekanan darah akan naik dengan pertambahan usia terutama setelah usia 60 tahun. Hal ini terjadi karena setelah umur 45 tahun dinding arteri akan mengalami penebalan oleh karena adanya penumpukan zat kolagen pada lapisan otot, sehingga pembuluh darah akan berangsur-angsur menyempit menjadi kaku (Anggaraini, 2009). Selanjutnya darah pada setiap denyut jantung dipaksa untuk melalui pembuluh darah yang sempit dari biasanya sehingga akan menyebabkan naiknya tekanan darah (Anggaraini, 2009).

Gambaran rata-rata penurunan tekanan darah selama tujuh hari pada masing-masing kelompok.

Penurunan Rata-Rata Tekanan Darah Sistolik Kelompok Intervensi sebelum dan sesudah perlakuan

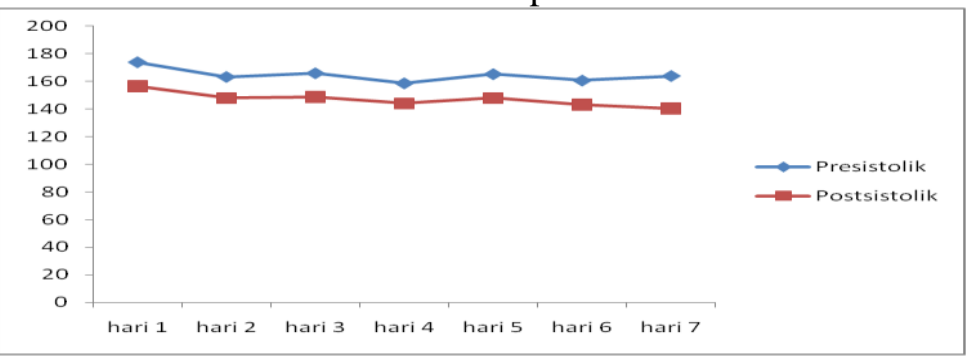

Berdasarkan grafik diatas, pada kelompok intervensi dapat diketahui bahwa gambaran rata-rata tekanan darah sistolik sebelum dan sesudah perlakuan selama 7 hari adalah mengalami penurunan setiap harinya. 
Penurunan Rata-Rata Tekanan Darah Diastolik Kelompok Intervensi sebelum dan sesudah perlakuan

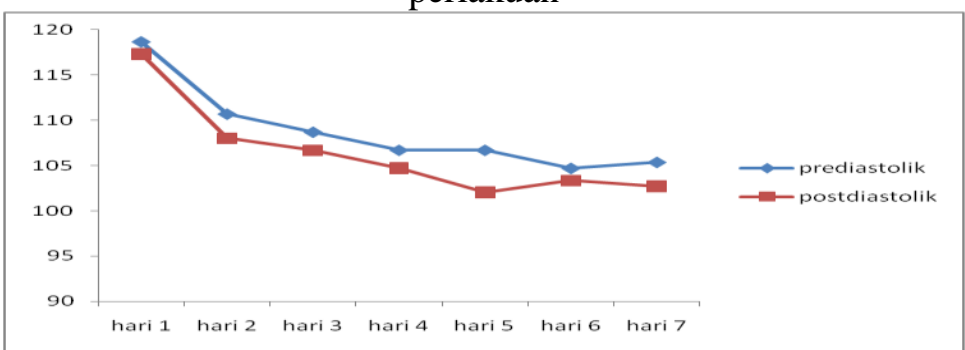

Berdasarkan grafik diatas, pada kelompok intervensi dapat diketahui bahwa gambaran rata-rata tekanan darah diastolik sebelum dan sesudah perlakuan selama 7 hari adalah mengalami penurunan dan naik dihari keenam dan turun dihari ketujuh.

Penurunan Rata-Rata Tekanan Darah Sistolik Kelompok Kontrol sebelum dan sesudah perlakuan

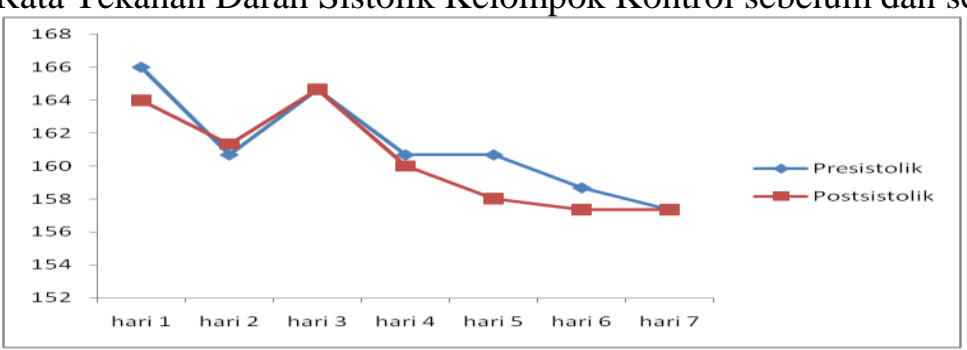

Berdasarkan grafik diatas, pada kelompok kontrol dapat diketahui bahwa gambaran rata-rata tekanan darah sistolik sebelum dan sesudah perlakuan selama 7 hari adalah mengalami turun naik setiap harinya.

Penurunan Rata-Rata Tekanan Darah Diastolik Kelompok Kontrol sebelum dan sesudah perlakuan

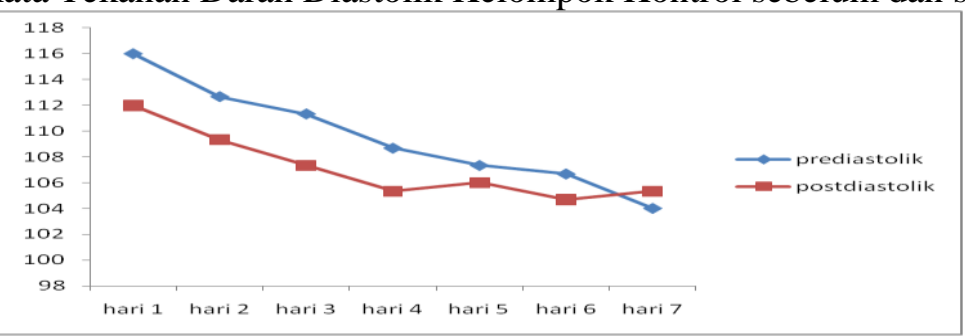

Berdasarkan grafik diatas, pada kelompok kontrol dapat diketahui bahwa gambaran rata-rata tekanan darah diastolik sebelum dan sesudah perlakuan selama 7 hari adalah mengalami penurunan dan naik dihari ketujuh.

Perbedaan Rata-rata Tekanan Darah Sebelum dan Sesudah kelompok intervensi

\begin{tabular}{|c|c|c|c|c|c|c|c|c|}
\hline & \multirow[t]{2}{*}{ Mean } & \multirow[t]{2}{*}{ SD } & \multirow[t]{2}{*}{ SE } & \multicolumn{2}{|c|}{$95 \%$ CL } & \multirow[t]{2}{*}{$\mathbf{T}$} & \multirow[t]{2}{*}{$\mathbf{N}$} & \multirow[t]{2}{*}{ P-Value } \\
\hline & & & & Low & Up & & & \\
\hline Sistolik & & & & & & & & \\
\hline Pretest & 174 & 8,281 & 2,138 & 19,463 & 31,204 & 31,255 & 15 & 0.000 \\
\hline Postest & 148,67 & 10,601 & 2,737 & & & & & \\
\hline Diastolik & & & & & & & & \\
\hline Pretest & 118,67 & 16,847 & 4,350 & 9,121 & 17,004 & 4,989 & 15 & 0.000 \\
\hline Postest & 102,67 & 10,328 & 2,667 & & & & & \\
\hline
\end{tabular}

Berdasarkan hasil uji t sampel berpasangan (paired $t$-test), maka dapat diketahui bahwa rata-rata tekanan darah sistolik sebelum mengkonsumsi jus apel sebesar $174 \mathrm{mmHg}$ dan rata-rata tekanan darah sistolik setelah mengkonsumsi jus apel $148,67 \mathrm{mmHg}$ atau mengalami penurunan sebesar 25,33. Sedangkan rata-rata tekanan darah diastolik sebelum mengkonsumsi jus apel sebesar 118,67 $\mathrm{mmHg}$ dan rata-rata tekanan darah diastolik setelah mengkonsumsi jus apel 102,67 $\mathrm{mmHg}$ atau mengalami penurunan sebesar 16,000. Dengan uji T paired test diperoleh nilai significancy $(P)$ value $=0,000$ atau lebih kecil dari alfa $<0,05$. Keputusan hipotesis yang diambil artinya terdapat pengaruh yang bermakna pada tekanan darah sistolik sebelum dan sesudah mengkonsumsi jus apel. 
Sedangkan hasil uji statistik paired test diperoleh nilai significancy $(P)$ value $=0,000$ atau lebih kecil dari alfa $<0,05$. Keputusan hipotesis yang diambil artinya terdapat pengaruh yang bermakna pada tekanan darah diastolik sebelum dan sesudah mengkonsumsi jus apel.

Apel merupakan obat alami penurun tekanan darah tinggi karena banyak mengandung kalium. Kalium bermanfaat untuk mengurangi sekresi renin yang menyebabkan penurunan angiotensin II sehingga vasokontriksi pembuluh darah berkurang dan menurunnya aldosteron sehingga reabsorbsi natrium dan air kedalam darah berkurang. Kalium juga mempunyai efek pompa Na-K yaitu kalium dipompa dari cairan ekstra seluler ke dalam sel dan natrium dipompa keluar sehingga kalium dapat menurunkan tekanan darah (Guyton, 2008).

Dengan demikian dapat disimpulkan bahwa terdapat pengaruh yang signifikan antara pemberian jus apel terhadap penurunan tekanan darah pada lansia hipertensi di Puskesmas Muara Kaman.

Perbedaan Rata-rata Tekanan Darah Sebelum dan Sesudah kelompok kontrol

\begin{tabular}{lcccccccc}
\hline & Mean & SD & SE & \multicolumn{2}{c}{$\mathbf{9 5 \%}$ CL } & T & N & P-Value \\
& & & & Low & Up & & & \\
\hline Sistolik & & & & & & & & \\
Pretest & 166 & 8,281 & 2,138 & $-1,744$ & 5,744 & 1,146 & 15 & 0.271 \\
$\begin{array}{l}\text { Postest } \\
\text { Diastolik }\end{array}$ & 164 & 10,556 & 2,726 & & & & & \\
Pretest & 112,67 & 15,796 & 4,079 & $-0,348$ & 15,014 & 2,048 & 15 & 0.000 \\
Postest & 105,33 & 10,601 & 2,737 & & & & & \\
\hline
\end{tabular}

Berdasarkan hasil uji t sampel berpasangan (paired t-test), maka dapat diketahui bahwa rata-rata tekanan darah sistolik sebelum sebesar $166 \mathrm{mmHg}$ dan rata-rata tekanan darah sistolik setelah 164 $\mathrm{mmHg}$ atau mengalami penurunan sebesar 2,000. Sedangkan rata-rata tekanan darah diastolik sebelum sebesar $112,67 \mathrm{mmHg}$ dan rata-rata tekanan darah diastolik setelah $105,33 \mathrm{mmHg}$ atau mengalami penurunan sebesar 7,333 mmHg. Dengan uji T Paired Test diperoleh nilai significancy (P) value $=0,271$ atau lebih besar dari alfa $>0,05$. Keputusan hipotesis yang diambil artinya tidak terdapat pengaruh yang bermakna pada tekanan darah sistolik pada kelompok kontrol.

Sedangkan hasil uji statistik dengan uji T Paired Test diperoleh nilai significancy $(\mathrm{P})$ value $=0,060$ atau lebih besar dari alfa $>0,05$. Keputusan hipotesis yang diambil artinya tidak terdapat pengaruh yang bermakna pada tekanan darah diastolik pada kelompok kontrol.

Pada kelompok kontrol ada penurunan tetapi tidak berpengaruh secara signifikan. Kelompok kontrol hanya dipantau tekanan darahnya setiap hari sehingga hanya mengkonsumsi obat-obat tekanan darah tinggi saja tanpa diberikan obat-obat non farmakologi.

Dengan demikian dapat disimpulkan bahwa tidak terdapat pengaruh yang signifikan pada kelompok yang tidak diberikan jus apel (kelompok kontrol).

Perbedaan selisih rata-rata tekanan darah sistolik kelompok intervensi dan sistolik kelompok kontrol

\begin{tabular}{lccccccc}
\hline Variabel & N & Mean & SD & SE & \multicolumn{2}{c}{ 95\% CL } & P-Value \\
& & & & & Low & Up & \\
\hline Sistolik & & & & & & & \\
Intervensi & 15 & 25,33 & 10,601 & 2,737 & 6,928 & 26,405 & 0.002 \\
Kontrol & 15 & 2,00 & 1,746 & 1,746 & & & \\
\hline
\end{tabular}

Perbedaan selisih rata-rata tekanan darah diastolik kelompok intervensi dan sistolik kelompok kontrol

\begin{tabular}{lccccccc}
\hline Variabel & N & Mean & SD & SE & \multicolumn{2}{c}{ 95\% CL } & P-Value \\
& & & & & Low & Up & \\
\hline Sistolik & & & & & & & \\
Intervensi & 15 & 16,00 & 12,421 & 3,207 & 0,457 & 16,877 & 0.039 \\
Kontrol & 15 & 7,33 & 13,870 & 3,581 & & & \\
\hline
\end{tabular}

Hasil uji statistik menggunakan uji independent samples $t$ test untuk mengetahui selisih rata-rata tekanan darah sistolik dan diastolik pada kelompok intervensi dan kelompok kontrol didapatkan 
nilai p-value 0,002 dan $0,039<0,05$, maka dapat disimpulkan bahwa ada perbedaan yang signifikan antara selisih rata-rata tekanan darah sistolik dan diastolik pada kelompok intervensi dan kelompok kontrol sebelum dan sesudah perlakuan.

Hipertensi adalah keadaan peningkatan tekanan darah yang memberi gejala yang akan berlanjut kesuatu organ target seperti stroke (untuk otak), penyakit jantung koroner (untuk pembuluh darah jantung). Dengan target organ diotak yang berupa stroke, hipertensi menjadi penyebab utama stroke yang membawa kematian yang tinggi (Bustan, 2007). Sehingga untuk mengatasinya kita bisa menggunakan obat-obatanantihipertensi atau bisa menggunakan obat non farmakologi seperti buah dan sayuran yang bisa digunakan untuk mengatasi hipertensi salah satunya adalah buah apel.

Apel (Malus Sylvestris) mengandung kalium yang tinggi. Kalium bisa menstabilkan tekanan darah. Apel telah diketahui sebagai sumber yang kaya senyawa antioksidan dan kimia yang disebut flavonoid yang sehat untuk jantung dan baik untuk sistem kardiovaskuler pada umumnya, sehingga jika jantung sehat maka tekanan darah juga akan sehat. Kandungan zat gizi yang menonjol pada apel adalah kalium, terutama apel berwarna merah tergolong memiliki kandungan kalium cukup tinggi. Kalium meningkatkan ekskresi Na dan menurunkan sekresi rennin, vasodilatasi arteriol dan menurunkan respon terhadap vasokonstriktor endogen. Apel juga mengandung serat, flavonoids, dan fruktosa. Dalam $100 \mathrm{~g}$ apel terdapat $2,1 \mathrm{~g}$ serat. Apabila kulitnya dikupas, maka kandungan serat apel masih tetap tinggi yakni 1,9 g. Serat apel mampu menurunkan kadar kolesterol darah dan resiko penyakit jantung koroner dan menurunkan tekanan darah, sedangkan didalam apel sendiri banyak mengandung kalium fungsi kalium sendiri adalah mengatur kerja jantung yang mempengaruhi kontraksi otot-otot jantung, mengatur keseimbangan cairan tubuh bersama natrium, berperan dalam vasodilatasi arteriol sehingga TPR menurun demikian juga dengan tekanan darah. Dan kalium juga bisa mempengaruhi system renin angiotensin, dimana kalium menghambat pengeluaran renin yang seharusnya mengubah angiotensinogen menjadi angiotensin I, karena adanya blok pada sistem ini maka pembuluh darah akan mengalami vasodilatasi sehingga akan terjadi relaksasi pada dinding pembuluh darah yang akhirnya akan menurunkan tekanan darah, selain itu kalium juga menurunkan pengeluaran aldosteron, sehingga ekskresi natrium dan air oleh ginjal meningkat, sehingga cairan atau volume intravaskuler menurun, maka tekanan darah akan ikut menurun (Guyton, 2008).

Serat tak larut dalam apel berfungsi untuk mengikat kolesterol LDL dalam saluran cerna dan kemudian menyingkirkannya dari tubuh. Sementara itu, serat larutnya (pektin) akan mengurangi produksi kolesterol LDL di hati, menurunkan kolesterol, dan bermanfaat untuk mengatasi diare karena kemampuannya membentuk agar tetap lunak serta tidak cair. Kulit apel mengandung flavonoid yang disebut quercitin. Quercitin ini mempunyai aktivitas antioksidan yang tinggi. Fungsinya adalah mencegah serangan radikal bebas sehingga dapat melindungi tubuh dari kemungkinan serangan kanker.

Walaupun demikian, jus apel tidak menurunkan tekanan darah kembali normal tetapi jus apel dapat menjadi alternatif selain obat yang dapat digunakan untuk mengendalikan tekanan darah pada lansia yang menderita hipertensi. Kandungan apel tersebut memiliki berbagai macam mekanisme untuk menurunkan tekanan darah, seperti yang dikemukakan oleh teori diatas sehingga tekanan darah dapat turun setelah pemberian jus apel. Pengendalian tekanan darah sangat penting untuk mencegah seseorang seperti pecahnya pembuluh darah dari komplikasi hipertensi sehingga terjadi perdarahan yang dapat terjadi di otak dan jantung sehingga dapat mengakibatkan stroke,gagal jantung bahkan kematian. Dari penelitian ini yang mendukung para lansia sehingga tekanan darah menurun yaitu selama penelitian lansia dikontrol pola makan seperti asupan garam dan pola istirahat pada lansia yang menderita hipertensi teratur sehingga dengan jus apel ini dapat menurunkan tekanan darah.

Dari uraian diatas dapat disimpulkan bahwa mengkonsumsi jus apel merupakan salah satu faktor yang dapat menurunkan tekanan darah pada lansia hipertensi dan terdapat pengaruh antara kelompok intervensi dan kelompok kontrol pretest dan posttest terhadap penurunan tekanan darah pada lansia yang menderita hipertensi. 


\section{KESIMPULAN}

Kesimpulan yang dapat diambil dari tujuan penelitian ini diantaranya :

1. Usia rata-rata responden dalam penelitian ini adalah 65,8-69,6 tahun untuk kelompok intervensi sedangkan kelompok kontrol usia rata-rata responden adalah 63,12-67,15 tahun. jumlah responden perumpuan lebih banyak dari pada laki-laki.

2. Pada kelompok intervensi dapat diketahui bahwa rata-rata tekanan darah sistolik sebelum mengkonsumsi jus apel adalah $174 \mathrm{mmHg}$, dan rata-rata tekanan darah diastolik sebelum mengkonsumsi jus apel adalah 118,67 $\mathrm{mmHg}$. sedangkan rata-rata tekanan darah sistolik sesudah mengkonsumsi jus apel adalah $148,67 \mathrm{mmHg}$, dan rata-rata tekanan darah diastolik sesudah mengkonsumsi jus apel adalah 102,67 mmHg.

3. Pada kelompok kontrol dapat diketahui bahwa rata-rata tekanan darah sistolik sebelum adalah $166 \mathrm{mmHg}$, dan rata-rata tekanan darah diastolik sebelum adalah 112,67 $\mathrm{mmHg}$. sedangkan rata-rata tekanan darah sistolik sesudah adalah $164 \mathrm{mmHg}$, dan rata-rata tekanan darah diastolik sesudah adalah $105,33 \mathrm{mmHg}$.

4. Hasil uji Paired t-test kelompok intervensi dan kelompok kontrol. Hasil uji statistik menunjukan nilai rata-rata pretest dan posttest pada kelompok intervensi $<0,05$ maka disimpulkan bahwa Ho ditolak, sedangkan hasil uji statistik menunjukan nilai rata-rata pretest dan posttest pada kelompok kontrol >0,05 maka disimpulkan bahwa Ho diterima.

5. Hasil uji Independent t-test kelompok intervensi dan kelompok kontrol diperoleh hasil p-value 0,002 dan $0,039<0,05$ maka dapat disimpulkan bahwa Ho ditolak yang artinya ada perbedaan yang signifikan antara selisih rata-rata tekanan darah pada kelompok intervensi dan kelompok kontrol sebelum dan sesudah perlakuan.

\section{SARAN}

Penelitian ini memiliki beberapa saran yang dapat disampaikan yang diharapkan dapat bermanfaat, yaitu :

1. Bagi penderita hipertensi

Hasil penelitian ini di harapkan dapat memberikan pengetahuan dan manfaat dari jus apel terhadap penurunan tekanan darah pada lansia dengan hipertensi bagi penderita hipertensi sehingga hipertensi dapat diatasi dan dapat diterapkan dikehidupan sehari-hari.

2. Bagi tempat penelitian

Hasil penelitian ini diharapkan menjadi masukan penting bagi Puskesmas Muara Kaman yang tidak hanya mengandalkan obat-obat medis tetapi jus apel juga dapat menurunkan tekanan darah pada penderita hipertensi. Selain itu juga bisa menggunakan terapi herbal yang lain seperti dengan buah-buahan yang bisa mengendalikan atau menurunkan tekanan darah.

3. Bagi peneliti selanjutnya

Dapat dijadikan sumber untuk sumber data dalam melaksanakan penelitian lebih lanjut terutama tentang kombinasi antara buah apel dengan buah yang lainnya yang dapat membantu menurunkan hipertensi maupun penyakit lainnya atau dengan responden yang lebih banyak lagi dengan menggunakan rancangan anova.

\section{KEPUSTAKAAN}

Aiska, G. (2013). Perbedaan Penurunan Tekanan Darah Sistolik Lansia Hipertensi Yang diberi Jus Tomat (Lycopersicum Commune) Dengan Kulit Dan Tanpa Kulit. Mahasiswa Fakultas Kedokteran Universitas Diponegoro.

Amilawaty dkk. (2007). Hipertensi, Penerbit Kedokteran EGC, Jakarta.

Amran, Y. (2010). Pengaruh Tambahan Asupan Kalium Dari Diet Terhadap Penurunan Hipertensi

Sistolik dan Diastolik Tingkat Sedang pada Lanjut Usia. Artikel Penelitian Universitas Islam Negri Syarif Hasanuddin Jakarta.

Astawan. (2007). Cegah Hipertensi Dengan Pola Makan, Diperoleh dari http:202.155.5.44/index.php?option=articles\&task=viewarticle\&artid=20\&Itemid3 .

Aziza. (2007). Hipertensi : The Sillent Killer, Jakarta : Ikatan Dokter Indonesia.

Bandiyah, S. (2009). Lanjut Usia dan Keperawatan Gerontik-Geriatrik.

Braverman. (2006). Penyakit Jantung dan Penyembuhanya Secara Alami. Jakarta: Bhuana Ilmu Populer.

Dalimartha, S,et al. (2008). Care Your Self Hipertension. Jakarta: Penebar Plus. 
Diana. (2007). Bebas Hipertensi Dengan Terapi Jus Yogyakarta: Niaga Swadaya.

Guyton. (2009). Buku Ajar Fisiologi Kedokteran Edisi 11. EGC, Jakarta.

Mardiana, L. (2013). Ramuan dan Khasiat Kulit Manggis. Penebar Swadaya, Jakarta.

Sugiyono. (2010). Metode Penelitian Kuantitatif Kualitatif dan R \& D. Jakarta : AlfaBeta 